\title{
Synthesis of PI/POSS nanocomposite films based on track nuclear membranes and assessment of their resistance to oxygen plasma flow
}

\author{
N.I. Cherkashina ${ }^{\text {a, }}$, V.I. Pavlenko ${ }^{a}$, A.V. Noskov ${ }^{b}$, A.N. Shkaplerov ${ }^{c}$, A.A. Kuritsyn ${ }^{c}$, E. \\ V. Popova ${ }^{\text {c }}$, S.V. Zaitsev ${ }^{a}$, O.V. Kuprieva ${ }^{a}$, N.V. Kashibadze ${ }^{\text {a }}$ \\ ${ }^{a}$ Belgorod State Technological University Named After V.G. Shoukhov, Belgorod, 308012, Kostyukov str., 46, Russia \\ ${ }^{\mathrm{b}}$ Belgorod State National Research University, Belgorod, 308015, Pobedy str., 85, Russia \\ ${ }^{\mathrm{c}}$ Yu. A. Gagarin Research and Test Cosmonaut Training Center, Moscow, Russia
}

\section{A R T I C L E I N F O}

\section{Keywords:}

Track membranes

Nanocomposite films

Oxygen plasma

\begin{abstract}
A B S T R A C T
This work presents, for the first time, data on the possibility of synthesizing polyimide nanocomposite films based on track nuclear membranes and organosiloxane (polyhedral oligomeric silsesquioxanes) POSS structures. The synthesis of the nanocomposite films was carried out by filling the tracks of a polyimide membrane with POSS structures under hydrothermal conditions in a high-pressure reactor. The surface and mechanical characteristics of the developed nanocomposite films were studied, and the results of their resistance to the flow of oxygen plasma are presented. It was found that the introduction of POSS structures significantly increased the resistance of polyimide to the flow of oxygen plasma. The PI/POSS composite exhibited an insignificant change in weight, the weight loss reached $0.92 \pm 0.05 \mathrm{mg} / \mathrm{cm}^{2}$ in $24 \mathrm{~h}$ after the start of the experiment, which is almost two orders of magnitude lower than that of the polyimide film.
\end{abstract}

\section{Introduction}

Polymer materials based on polyimide (PI) are widely used in the design of modern spacecraft (SC). The combination of high strength, retained even after exposure to space radiation, high and low temperature stability, and UV irradiation makes it possible to consider PI as a promising material for creating elements of space technology with improved energy-mass characteristics [1,2]. Various thermoregulatory coatings, elements of screen-vacuum thermal insulation, and sun protection devices, etc. are created from PI [3].

The disadvantage of products made of PI is their low resistance to atomic oxygen, which is the main component of the Earth's atmosphere at altitudes of $\sim 200-800 \mathrm{~km}$ [4-6]. Therefore, for low-orbit spacecraft operating in the specified altitude range, an extremely urgent problem is the protection of PI materials on the surface of the spacecraft from the destructive effect of the flow of atomic oxygen (AO). Under the influence of $\mathrm{AO}$ on PI, material is carried away from the surface and the formation of a carpet-like surface morphology occurs [7-9].

There are several ways to protect PI from atomic oxygen. For example, the introduction of various fillers in $\mathrm{PI}$, such as $\mathrm{Al}_{2} \mathrm{O}_{3}, \mathrm{TiO}_{2}$, WC, $\mathrm{ZrO}_{2}$, multiwalled carbon nanotubes, and detonation nanodiamonds [10-12]. Another method is the deposition of oxygen-resistant coatings on the PI surface which create a kind of barrier that prevents the penetration of oxygen atoms into the deep layers of the polymer [13,14]. Chunbo et al. [15] found that silver plating of polyimide films, as well as their surface modification by poly (siloxane amic acid) ammonium salts, leads to a several-fold decrease in weight loss after treatment with atomic oxygen. In another work by Liu et al. [16], a polysilazane synthesized by aminolysis of a dichloromethylviny coating was used to protect the Kapton brand PI. It was found that the erosion yield of the Kapton was decreased by about two orders of magnitude. After exposure, the coated Kapton still had a smooth surface and its optical properties were still at a high level. Mu et al. in their study [17] showed the possibility of protecting PI from atomic oxygen by creating a protective $\mathrm{SiO}_{\mathrm{x}}$ film on it.

Another promising method for protecting PI from the action of atomic oxygen in space is the introduction of silicon-containing structures [18-21]. Many works have been devoted to the study of increasing the stability of polymers, especially PI, by introducing polyhedral oligomeric silsesquioxanes (POSS-structures) into them, with the general formula $\left[\mathrm{RSiO}_{1,5}\right] \mathrm{n}$, where $\mathrm{R}$ is an organic radical, including those carrying a reactive group, and $n=6,8,10 \ldots$ [22-24]. During exposure

\footnotetext{
* Corresponding author.

E-mail address: cherkashina.ni@bstu.ru (N.I. Cherkashina).
} 
of POSS PI to atomic oxygen, the organic material is degraded and a silica passivation layer is formed. This silica layer protects the underlying polymer from further degradation [25].

A sample containing $15 \mathrm{wt} \%$ POSS in PI only reached an erosion rate of $68 \%$ of the erosion rate of pure PI [26]. PI-based nanocomposite films, incorporating POSS and carbon nanotube (CNT) additives, were studied in Ref. [27]. CNT - POSS - PI films with $15 \mathrm{wt} \%$ POSS content exhibited an erosion yield of $4.8 \times 10^{-25} \mathrm{~cm}^{3} \mathrm{O}$ atom ${ }^{-1}$ under a $2.3 \times 10^{20} \mathrm{O}$ atoms $\mathrm{cm}^{-2} \mathrm{AO}$ fluence, roughly one order of magnitude lower than that of pure PI films.

The main disadvantage of introducing POSS nanoparticles into PI is the aggregation of particles into large conglomerates. In this case, an uneven distribution of particles throughout the volume of PI occurred which significantly reduced the protection against atomic oxygen [28]. To solve this problem, copolymerizing POSS monomers with the PI precursor was used to obtain a hybrid nanocomposite [29,30]. Despite this, it is not possible to completely protect against weight loss when exposed to atomic oxygen. The XPS data of the hybrid nanocomposite (PI/POSS) indicates that the carbon content of the near-surface region is decreased from 63.6 to 19.3 at $\%$ after AO exposure [31].

We have proposed a technology for introducing POSS structures into a PI by using PI track (nuclear) membranes as a PI matrix. Track membranes are the thinnest films, $10-25 \mu \mathrm{m}$ in size, in which there are many through holes - tracks on the nanoscale. Earlier, we obtained data on the possibility of synthesizing multilayer composites based on PI track membranes filled with nano-dispersed fillers [32,33]. The introduction of POSS structures into the pores of track membranes will allow the filler to be uniformly distributed throughout the entire volume of the PI matrix and prevent the formation of POSS conglomerates, which is impossible with other methods of composite synthesis.

This paper presents the possibility of creating PI/POSS nanocomposite films based on PI track (nuclear) membranes and the results of their resistance to the flow of oxygen plasma.

\section{Materials and methods}

\subsection{Synthesis}

A PI film of PM-1 brand (Institute of Plastics OJSC, Moscow, Russia) was used as the PI sample. The film thickness was $25 \mu \mathrm{m}$. PI (nuclear) track membranes, manufactured by Ion track technology for innovative products (it4ip, Belgium), were used as a polymer matrix for the creation of nanocomposite films. The pore diameter was $200 \mathrm{~nm}$, the pore density was $5 \times 10^{8} \mathrm{~cm}^{-1}$, and the PI membrane was $25 \mu \mathrm{m}$ thick. Fig. 1 shows micrographs of the used PI track membrane at various magnifications.

The tracks of the PI membrane were filled with organosilicon

a

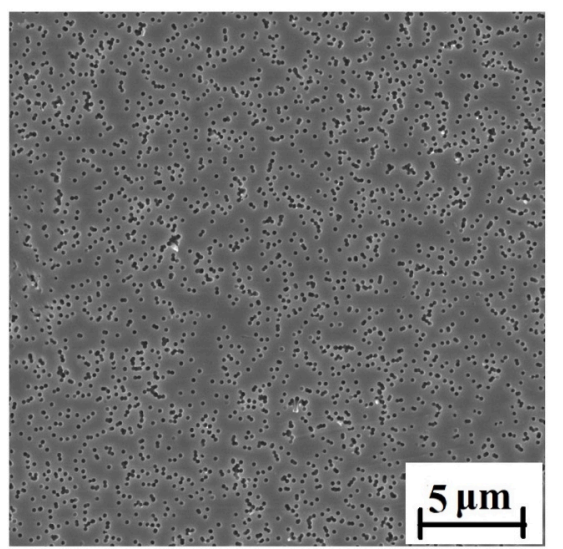

structures - POSS particles. The tracks of the nuclear PI membrane were filled with organosiloxane structures by synthesizing the filler in a GSA-0.3 high-pressure reactor in the presence of PI membranes (autoclaving temperature $250{ }^{\circ} \mathrm{C}$, holding time $4 \mathrm{~h}$ ).

Cyclohexyl trichlorosilane $\mathrm{C}_{6} \mathrm{H}_{11} \mathrm{SiCl}_{3}$ (manufactured by PAO Khimprom, Novocheboksarsk, Russia) and silicon tetrachloride $\mathrm{SiCl}_{4}$ (OOO KHORST, Moscow, Russia) were used as reagents for the synthesis of POSS. POSS was synthesized in a $99.75 \%$ purity acetone solution (OOO Komponent-Reaktiv, Moscow, Russia). The synthesis of organosiloxane structures (POSS) under hydrothermal conditions in a highpressure reactor is described in more detail in Ref. [34].

\subsection{Atomic oxygen treatment}

Simulation tests on the effect of the flow of atomic oxygen in space were carried out on a setup generating a beam of oxygen atoms by means of an electric discharge in a gas mixture containing oxygen, with further effusion of oxygen atoms from the chamber. The samples were treated in the positive column of a direct current discharge in oxygen. Using this method allows one to obtain fluxes of oxygen atoms with an energy of $5-10 \mathrm{eV}$ [35]. The discharge was excited in a glass reactor, $3 \mathrm{~cm}$ in diameter, at a gas pressure of $0.1 \mathrm{~Pa}$ and a discharge current of $120 \mathrm{~mA}$. The attainable flux density of atomic oxygen $\mathrm{O}(3 \mathrm{P})$ in the experiment was $5 \times 10^{16}$ atom $\cdot \mathrm{cm}^{-2} \cdot \mathrm{s}^{-1}$.

Under orbital flight conditions, the static density of atomic oxygen at an altitude of $300 \mathrm{~km}$ is of the order of $\rho \sim 10^{9}$ atom $/ \mathrm{cm}^{3}$. At a spacecraft speed of $8 \mathrm{~km} / \mathrm{s}(\mathrm{E}=5 \mathrm{eV})$, this static density of oxygen atoms turns into a powerful stream of neutral oxygen atoms, which reaches $10^{15}$ atom/ $\left(\mathrm{cm}^{2} \cdot \mathrm{s}\right)$. The total fluence of the flow of atomic oxygen during a year of orbital flight at an altitude of $300 \mathrm{~km}$ is $\mathrm{F} \sim 10^{22}$ atom $/ \mathrm{cm}^{3}$ [36].

Since the obtained simulation parameters of oxygen plasma differed from real conditions in outer space, the concept of an equivalent (effective) fluence was used as a quantitative measure of exposure. Equivalent fluence is the fluence of an atomic oxygen flux with an energy of $5 \mathrm{eV}$, which provides the same mass loss of the witness sample. In accordance with the US standard ASTM [37], PI of the KaptonH brand was used as a reference material.

\subsection{Research methods}

Weighing of all samples before and after treatment in a flow of atomic oxygen was conducted outside the chamber on a CAUW-220D (CAS) analytical balance with an accuracy of $0.01 \mathrm{mg}$. Based on the weighing results for each of the samples, the specific weight loss $\Delta \mathrm{m}$ was calculated:

b

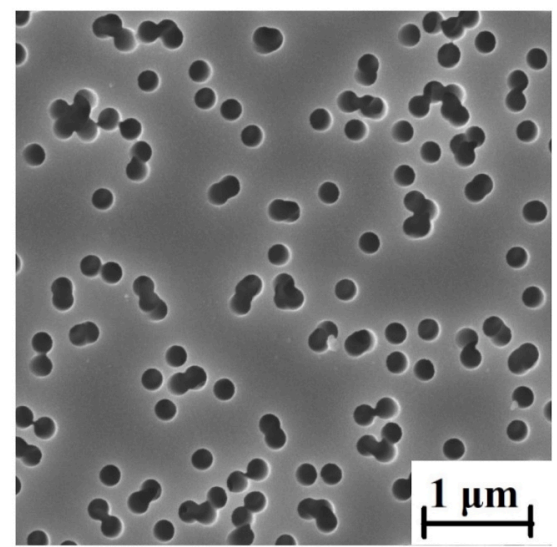

Fig. 1. SEM images of the used PI track (nuclear) membrane. 
where $\mathrm{m}$ is the total weight loss of the sample, and $\mathrm{S}$ is the area of the sample surface treated with oxygen plasma.

The equivalent fluence of atomic oxygen $\left(\mathrm{F}_{\mathrm{m}}\right)$ was determined from the change in the mass $(\mathrm{m})$ of the film of the witness sample (Kapton $\mathrm{H}$ film), with the known values of the mass erosion coefficient:

$F=\Delta m_{k} / R_{k}$

where $R_{k}$ is the erosion coefficient of the Kapton $H$ reference specimen.

For scanning electron microscopy, a TESCAN MIRA 3 LMU field emission electron microscope (TESCAN, Czech Republic) was used.

Probe scanning microscopy was carried out on an Ntegra-Aura scanning probe microscope. The studies were performed in continuous or intermittent contact modes on an Ntegra-Aura instrument (NT-MDT Company, Zelenograd, Russia) using commercial Si, or SiN cantilevers (NSG01, NT-MDT, Russia), under atmospheric conditions and low vacuum. Processing and construction of atomic force microscopy (AFM) images was performed using the software NOVA (NT-MDT, Russia) and ImageAnalysis (NT-MDT, Russia).

The quantitative assessment of the mechanical properties (microhardness, elastic modulus) of the films was performed by the nanoindentation method using a Berkovich nanoindentor model $750 \mathrm{Ubi}$ (Hysitron, United States), with a radius of curvature of $100 \mathrm{~nm}$ at a load of $300 \mu \mathrm{N}$. Studies of mechanical properties was carried out on at 5 different points on the surface of samples. Quantitative data were determined taking into account the Student parameter and standard deviation. Topography and properties were determined from both sides of the test samples.

\section{Results and discussion}

\subsection{SEM characteristic of PI/POSS composites}

Fig. 2 shows microscopic data on the surface of a PI membrane after joint exposure in a high-pressure reactor with a powder of polyhedral oligosilsesquioxane, of a partially condensed structure, and silicon tetrachloride at a temperature of $250{ }^{\circ} \mathrm{C}$. It can be seen that after $4 \mathrm{~h}$ of exposure, the pores were almost completely filled (Fig. 2a, c).

To assess the filling of the membrane pores with POSS structures, a cross-section SEM of the PI/POSS composite was performed. Fig. 3 shows the cross-section SEM of the PI/POSS composite synthesized with $4 \mathrm{~h}$ hydrothermal exposure. Analysis of the data in Fig. 3 showed that exposure under hydrothermal conditions leads not only to surface sedimentation of POS, but also to filling the internal pore space.

Using mathematical calculations on the number of filled pores per unit area, it was calculated that according to the SEM data, $89 \%$ of the pores were filled under the indicated hydrothermal conditions. With an increase in the autoclaving time, a certain number of pores (11\%) remain unfilled (Fig. 2b, d), which may be due to mechanical contamination of some pores, as a result of which they were not filled with POSS structures. Moreover, in Fig. 2b and d, the growth process of organosiloxane structures through the membrane channels, and the beginning of the formation of a continuous POSS coating on the PI membrane, is observed. Thus, the optimal holding time of the membranes in a highpressure reactor at $250^{\circ} \mathrm{C}$ is $4 \mathrm{~h}$.

As a result of filling through holes in a membrane made of polyimide

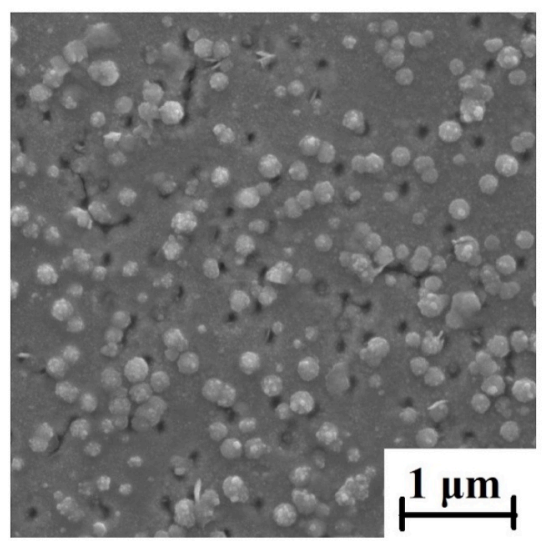

c

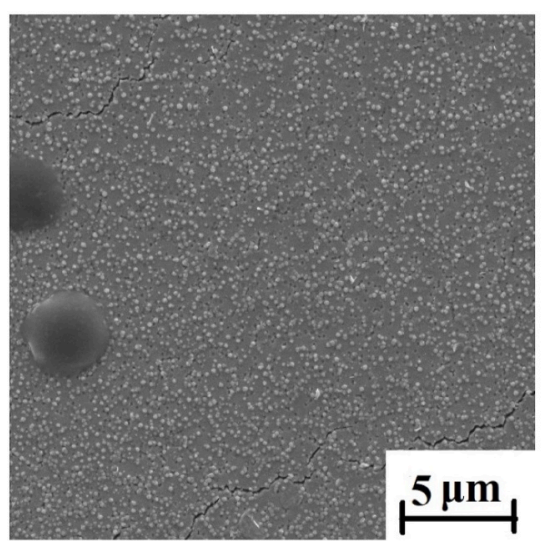

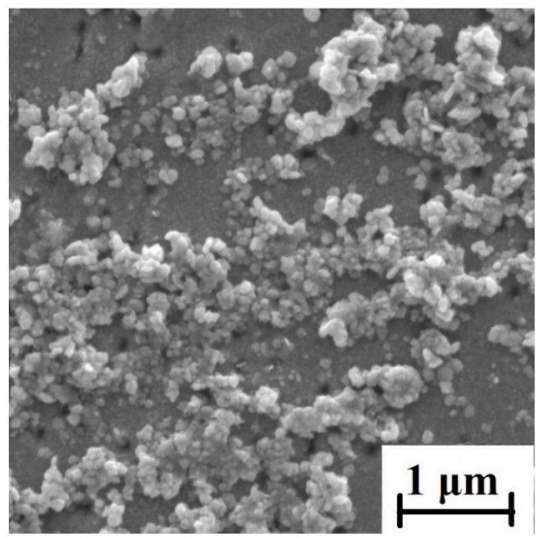

d

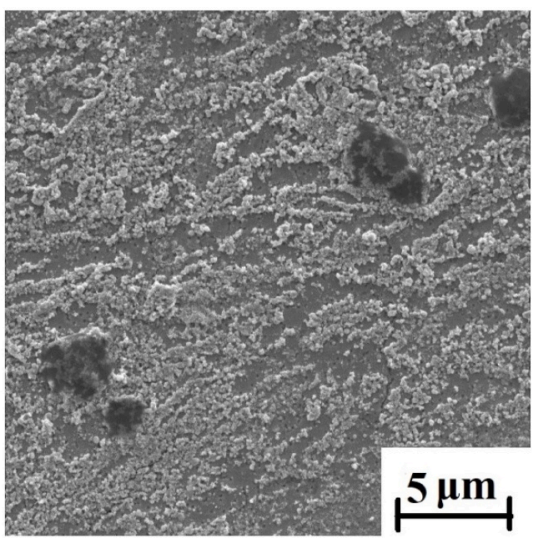

Fig. 2. SEM images of track membrane surfaces after hydrothermal exposure with reagents for: a, c $-4 \mathrm{~h}, \mathrm{~b}, \mathrm{~d}-5 \mathrm{~h}$. 


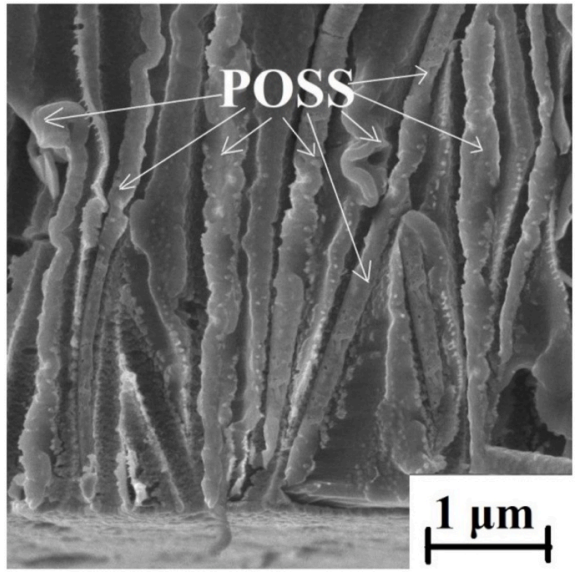

Fig. 3. SEM image of the cross-section of the PI/POSS composite synthesized with $4 \mathrm{~h}$ hydrothermal exposure.

(dielectric) with POSS (dielectric), friction occurs between them, resulting in a triboelectric effect. The triboelectric effect is the process of an electric charge flowing from one material to the surface of another when they come into contact with each other. The result is a contact potential difference and, as a consequence, the attraction of materials. Since, in our case, the area of contact between the filler and the membrane is large enough, the attraction force of the polyimide and the filler is very high. That contributes to the far-sightedness of the developed material.

\subsection{Weight loss after exposure to AO}

Fig. 4 shows the kinetics of weight loss for a film made of PI grade PM-1, and a composite based on a PI tracked nuclear membrane filled with POSS structures. Fig. 4 shows the average values of the weight loss considering measurements at five identical samples, and also shows the confidence interval of values considering the Student parameter and standard deviation for PI. For PI/POSS the confidence interval is too small and merges with the weight loss curve.

As shown in Fig. 4, the mass of the PI film decreased continuously and reached a weight loss value of $18.1 \pm 0.9 \mathrm{mg} / \mathrm{cm}^{2}$ in $24 \mathrm{~h}$ after the start of the experiment. The data obtained on the weight loss of the PI film at the indicated fluence agree with the known data presented in Ref. [38]. The PI/POSS composite exhibited a negligible change in weight, the weight loss reached $0.92 \pm 0.05 \mathrm{mg} / \mathrm{cm}^{2}$ in $24 \mathrm{~h}$ after the start of the experiment, which is almost two orders of magnitude lower than that of the PI film.

Based on the data in Fig. 4, the erosion yields of the studied samples were calculated from the weight loss using the following formula [29]:

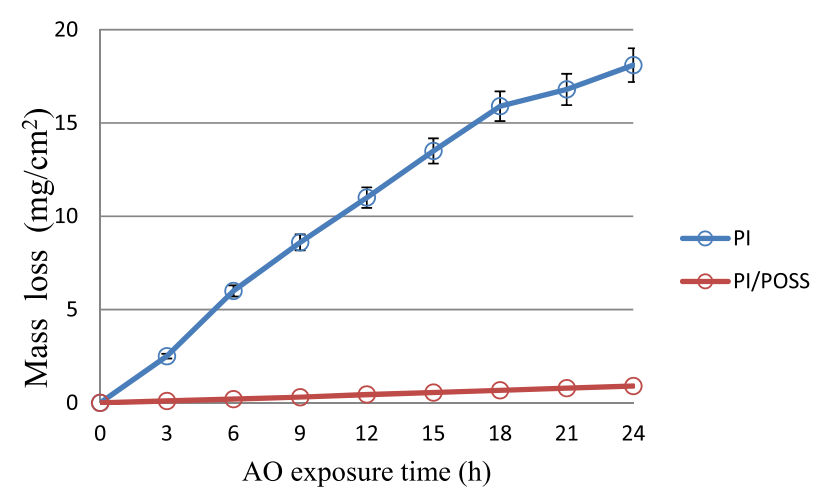

Fig. 4. Kinetics of mass loss after treatment with an oxygen plasma flow.

$$
\mathrm{E}_{\mathrm{S}}=\Delta \mathrm{m} /(\rho \cdot \mathrm{S} \cdot \mathrm{F})
$$

where, Es- erosion yield of the sample ( $\left.\mathrm{cm}^{3} / \mathrm{atom}\right), \Delta \mathrm{m}$ - mass loss of the sample $(\mathrm{g}), \mathrm{S}$ - surface area of the sample exposed to atomic oxygen attack $\left(\mathrm{cm}^{2}\right), \rho$ - density of the sample $\left(\mathrm{g} / \mathrm{cm}^{3}\right)$, and $\mathrm{F}=$ atomic oxygen fluence (atoms $/ \mathrm{cm}^{2}$ ).

The calculated value of erosion yield of PI was $~ 3.05 \times 10^{-24} \mathrm{~cm}^{3} /$ atom which was consistent with the data from flight experiments abroad [39]. The calculated value of erosion yield of PI/POSS was $\sim 0.15 \times$ $10^{-24} \mathrm{~cm}^{3} /$ atom $^{3}$.

\subsection{Changes in PI surface structure after exposure to $A O$}

Fig. 5 shows a SEM image of the surface of a PM-1 PI film before (a) and after $24 \mathrm{~h}$ of treatment (b) in an oxygen plasma flow.

The initial surface of the PI film has a fairly smooth relief (Fig. 5a). Despite the fact that the PI is amorphous-crystalline, individual grains in the original film are indistinguishable. However, small bumps are noticeable, which are most likely due to the inclusion of dust at the time of the industrial production of the film. After treatment of the PI film with an oxygen plasma flow, a strong change in the surface morphology is noticeable; it acquires a pile-like morphology (Fig. 5b), which is typical for most polymers irradiated with oxygen plasma [40-42]. The appearance of a granular relief is noticeable, formed by depressions and raised sections of a conical and acicular shape, oriented towards the flow of the oxygen plasma (Fig. 5b).

Fig. 6 shows the topography of the surface of the PI film before (a, c) and after 24-h treatment in a flow of oxygen plasma (b, d), obtained by atomic force microscopy (AFM). The studies were carried out in areas of $10 \times 10 \mu \mathrm{m}$.

Analysis of the 3D image shows (Fig. 6a) that the original surface is smooth (the large protrusion in the image in the upper corner is most likely associated with dust inclusions at the time of industrial production of the film, which were also noticeable in the SEM image of the original film (Fig. 5a)). After treatment with an oxygen plasma flow, the topography of the film changes greatly (Fig. 6b) with noticeable deep depressions, reaching depths of up to $120 \mathrm{~nm}$. Based on the data of the histogram of the distribution of protrusions (Fig. $6 \mathrm{c}$ and d), the roughness parameters of the PI film, up to and after treatment with oxygen plasma, showed a significant increase in the surface roughness of the PI film after treatment with an oxygen plasma flow (Table 1).

\subsection{Changes in the surface structure of PI/POSS after exposure to AO}

Fig. 7 shows a SEM image of the surface of a PI/POSS nanocomposite synthesized with $4 \mathrm{~h}$ hydrothermal exposure after 24-h treatment in an oxygen plasma flow. Fig. 2 shows a SEM image of the surface of the same sample of PI/POSS nanocomposite synthesized with $4 \mathrm{~h}$ hydrothermal exposure before treatment in an oxygen plasma flow.

Analysis of the data obtained in Fig. 7 shows that after the treatment of the PI/POSS nanocomposite film with an oxygen plasma flow, a significant change in the surface occurs, compared to the initial nanocomposite film surface, shown in Fig. 2. In Fig. 7, the appearance of many new particles covering the composite surface is clearly visible. These particles are generally spherical or oval in shape, and range in size from $300 \mathrm{~nm}$ to $\sim 2.5 \mu \mathrm{m}$. According to the results of electron probe microanalysis, it was found that the new formed particles consist of $\mathrm{Si}$ and $\mathrm{O}$ atoms (the depth of electron scanning at the studied points at $7 \mathrm{kV}$ did not exceed $50 \mathrm{~nm}$ ). The formation of these particles occurs due to the process of coagulation of POSS particles which are released as a result of the destruction of the PI component during treatment with the oxygen plasma flow. Further interaction of the aggregates with the oxygen plasma leads to the oxidative destruction of their organic fragments and the formation of inorganic $\mathrm{SiO}_{2}$ particles.

Thus, microanalysis of the surfaces of the nanocomposite film after treatment with an oxygen plasma flow shows that the chemical 
a

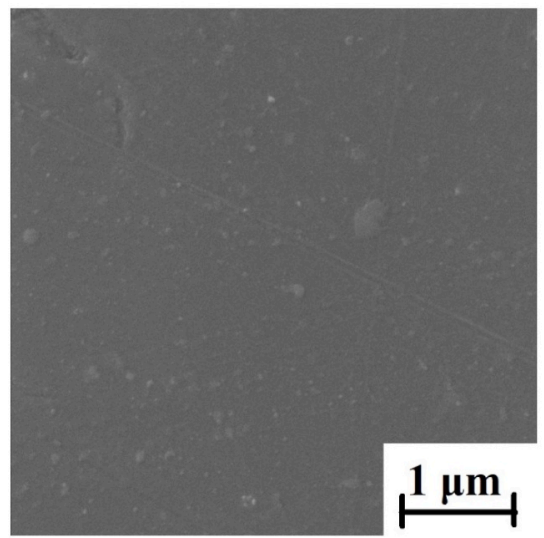

b

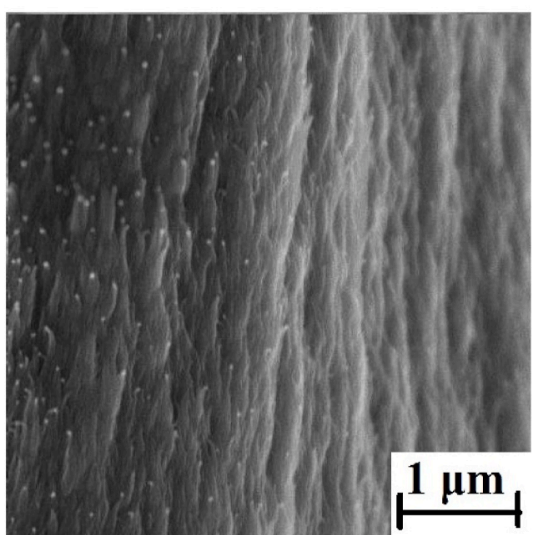

Fig. 5. SEM images of the surface of the PM-1 film before (a) and after 24-h treatment in an oxygen plasma flow (b).

a

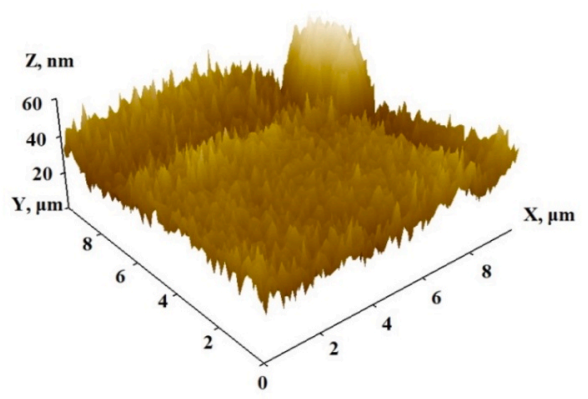

c

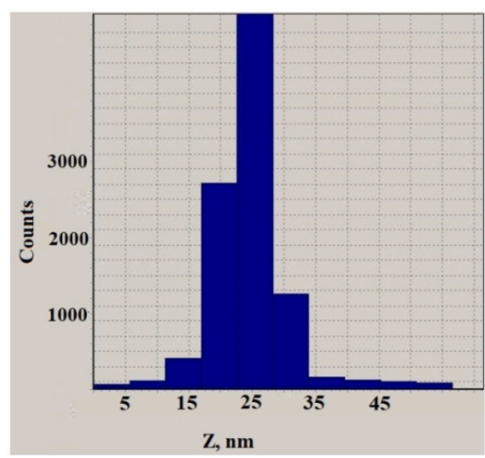

b

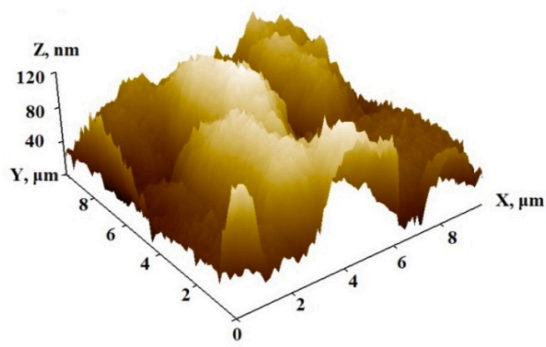

$\mathrm{d}$

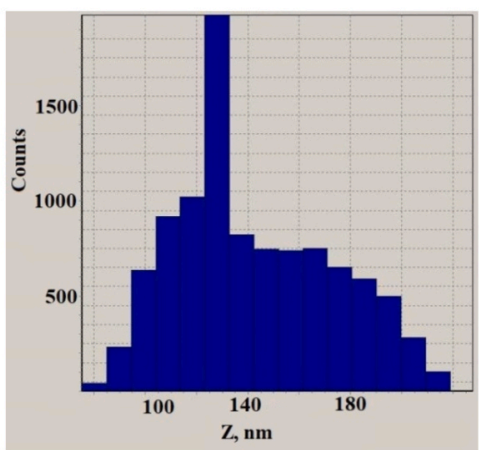

Fig. 6. Topography of the surface of the PI film before (a, c) and after 24-h treatment in an oxygen plasma flow (b, d): a, b - three-dimensional image; c, d - histogram of the distribution of protrusions.

Table 1

Values of the main statistical parameters of the surface roughness of the PI film before and after treatment with an oxygen plasma flow.

\begin{tabular}{|c|c|c|c|}
\hline \multirow[t]{2}{*}{ No } & \multirow{2}{*}{$\begin{array}{l}\text { Roughness parameter } \\
\text { name }\end{array}$} & \multicolumn{2}{|l|}{ Value } \\
\hline & & $\begin{array}{l}\text { Before oxygen plasma } \\
\text { treatment }\end{array}$ & $\begin{array}{l}\text { After oxygen plasma } \\
\text { treatment }\end{array}$ \\
\hline 1. & Sample size & 65,536 & 65,536 \\
\hline 2. & Maximum, nm & 56 & 219 \\
\hline 3. & Minimum, nm & 0 & 0 \\
\hline 4. & $\begin{array}{l}\text { Average roughness, } \mathrm{S}_{\mathrm{a}}, \\
\mathrm{nm}\end{array}$ & 4.35 & 25.94 \\
\hline 5. & $\begin{array}{l}\text { Root mean square } \\
\text { roughness, } \mathrm{S}_{\mathrm{q}}, \mathrm{nm}\end{array}$ & 6.41 & 30.70 \\
\hline
\end{tabular}

interaction of the components of the PI/POSS nanocomposite film with oxygen plasma particles leads to the formation of silicon dioxide particles (Fig. 7). It is known that POSS structures, due to their chemical nature, are highly resistant to the flow of atomic oxygen because Si plays a major role in creating stable protective structures on the surface, in the form of non-volatile oxides or glass-like substances, when such materials are found in an aggressive environment. The improved resistance of these materials to the action of strong oxidants (including atomic oxygen) is based on the mechanism of surface conversion, i.e. the formation of a new dense oxide protective layer, which can be seen in Fig. 6 .

Fig. 8 shows the topography of the surface of the PI/POSS nanocomposite film before (a, c) and after 24-h treatment in a flow of oxygen plasma (b, d), obtained by atomic force microscopy (AFM). The studies were carried out in areas of $60 \times 60 \mu \mathrm{m}$. 


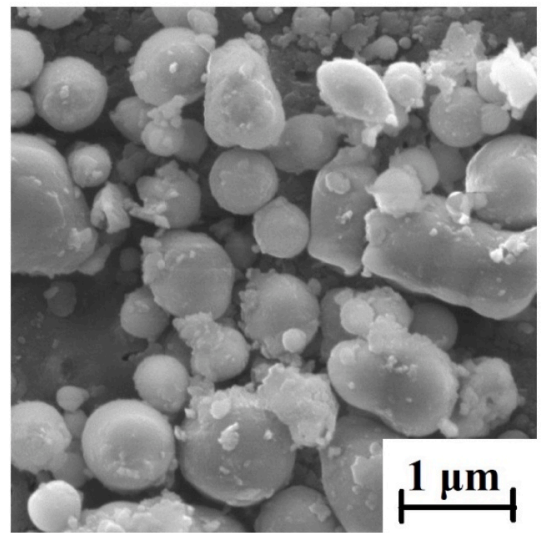

$\mathrm{b}$

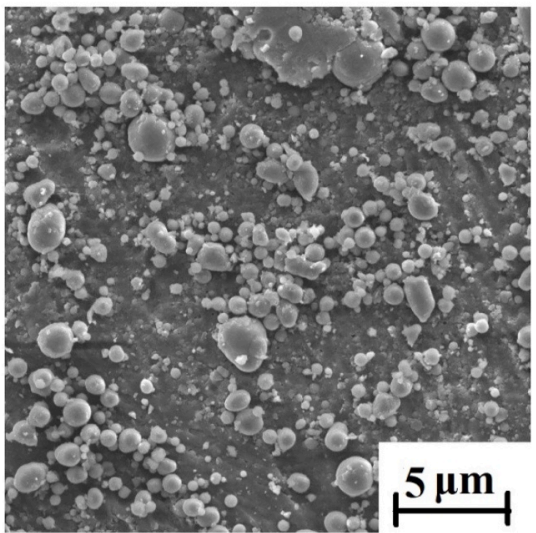

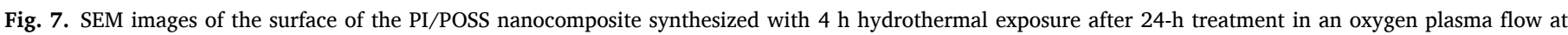
various magnifications.

a

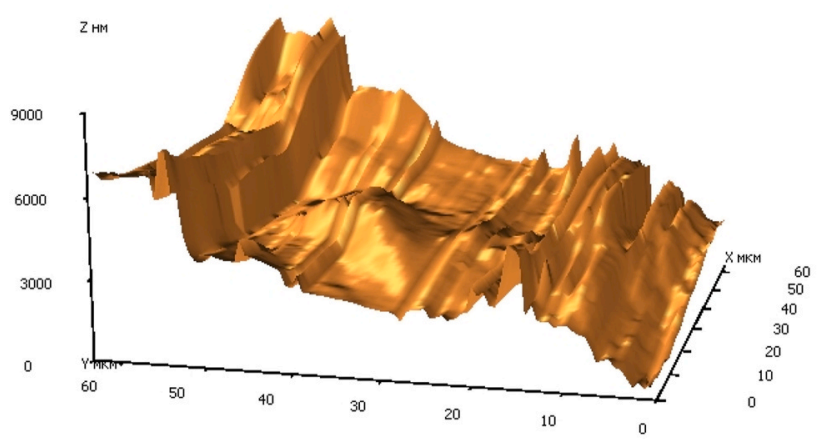

C

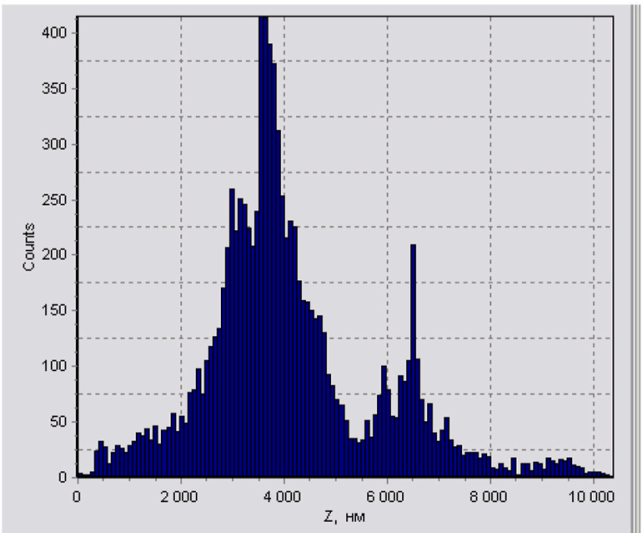

b

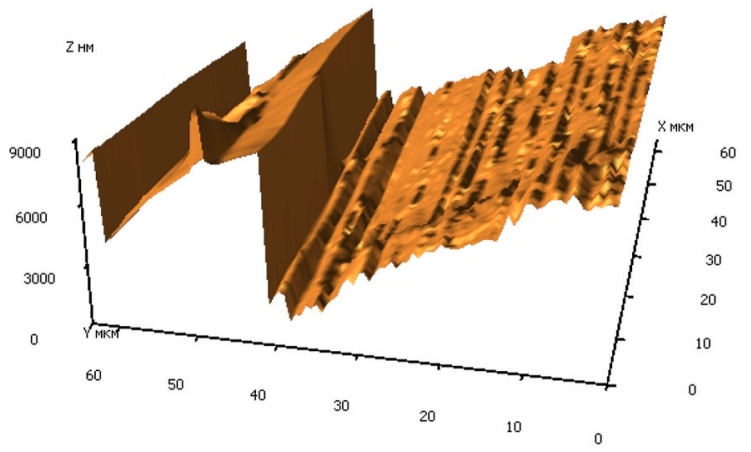

d

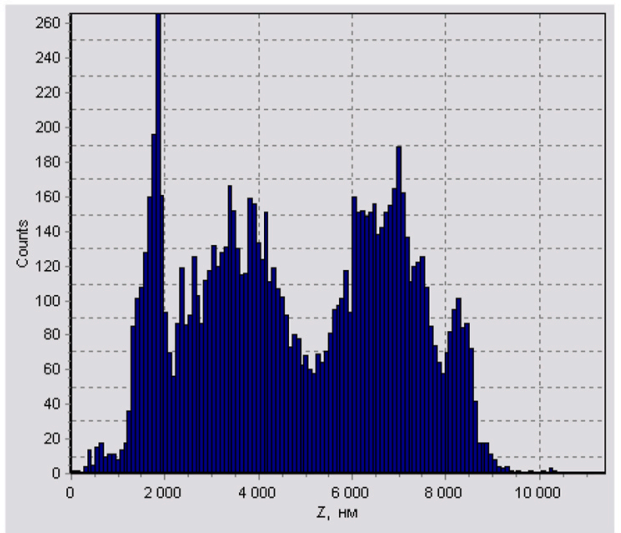

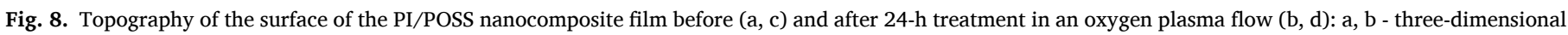
image; c, d - histogram of the distribution of protrusions.

After treatment with an oxygen plasma flow, the topography of the PI/POSS nanocomposite film changes (Fig. 8b). Based on the data of the histogram of the distribution of protrusions (Fig. $8 \mathrm{c}$ and d), the roughness parameters of the PI/POSS nanocomposite film, up to and after treatment with oxygen plasma, showed a significant increase in the surface roughness of the PI/POSS nanocomposite film after treatment with an oxygen plasma flow (Table 2).

\subsection{Changes in mechanical properties after exposure to $A O$}

The nanoindentation (NI) method was used to study the change in the mechanical behavior of the samples after exposure to an oxygen plasma flow. The NI method consists in precise local loading of the material surface with a specially certified probe, in this work a Berkovich diamond indenter, with simultaneous continuous recording of the kinetics of its immersion. The $\mathrm{P}-\mathrm{h}$ diagram obtained as a result of 
Table 2

Values of the main statistical parameters of the surface roughness of the PI/POSS nanocomposite film before and after treatment with an oxygen plasma flow.

\begin{tabular}{|c|c|c|c|}
\hline \multirow[t]{2}{*}{ No } & \multirow{2}{*}{$\begin{array}{l}\text { Roughness parameter } \\
\text { name }\end{array}$} & \multicolumn{2}{|l|}{ Value } \\
\hline & & $\begin{array}{l}\text { Before oxygen plasma } \\
\text { treatment }\end{array}$ & $\begin{array}{l}\text { After oxygen plasma } \\
\text { treatment }\end{array}$ \\
\hline 1. & Sample size & 65,536 & 65,536 \\
\hline 2. & Maximum, nm & 10,293 & 11,272 \\
\hline 3. & Minimum, nm & 0 & 0 \\
\hline 4. & $\begin{array}{l}\text { Average roughness, } S_{a} \text {, } \\
\mathrm{nm}\end{array}$ & 1274.8 & 1923.3 \\
\hline 5. & $\begin{array}{l}\text { Root mean square } \\
\text { roughness, } S_{\mathrm{q}}, \mathrm{nm}\end{array}$ & 1698.4 & 2186.1 \\
\hline
\end{tabular}

measurements is similar in meaning to the $\sigma-\varepsilon$ diagram; it allows one to determine the main mechanical characteristics of the material, such as hardness, yield stress, adhesion, local elastic modulus, and the proportion of elastic and plastic deformation under the indenter with respect to the total deformation, which determine the mechanical behavior and near-surface properties of the material at the nanometer level. The mechanical properties of the samples under study, before and after treatment with an oxygen plasma flow and obtained using the NI method, are presented in Table 3.

When using the nanoindentation method, by indenting the indenter in the direction normal to the film surface, the values of the local elastic modulus and microhardness on the surface of the initial PI film have fairly close values on both sides of the sample (Table 3). The small difference in values lies within the confidence interval due to the error of the instrument and the experiment. The close values of the local mechanical characteristics, determined on both surfaces of the film, shows the uniformity of the mechanical properties of the entire sample of the PI film and the uniformity of the phase composition over the whole volume.

After treatment with the flow of oxygen plasma, the modulus of elasticity and microhardness of the PI film decreased by $13 \%$ and $15 \%$, respectively, which is associated with the destruction of the surface layer of the polymer and the destruction of its chemical bonds. It should be noted that the mechanical indicators of the side of the oxygen plasma not directed to the flow showed little change $(\mathrm{E}=3.49 \pm 0.17 \mathrm{GPa} ; \mathrm{H}=$ $357 \pm 10 \mathrm{MPa}$ ). The slight deviation lies within the error of the experiment. Thus, the penetration (destruction) depth of atomic oxygen is insignificant in comparison with the film thickness $(25 \mu \mathrm{m})$. It is known that the flow of atomic oxygen only affects the surface properties

Table 3

Mechanical properties of the samples under study before and after treatment with an oxygen plasma flow.

\begin{tabular}{|c|c|c|c|}
\hline \multirow[t]{2}{*}{ No } & \multirow[t]{2}{*}{ Test sample } & \multicolumn{2}{|l|}{ Parameters } \\
\hline & & $\begin{array}{l}\text { Elastic } \\
\text { modulus (E), } \\
\text { GPa }\end{array}$ & $\begin{array}{l}\text { Microhardness } \\
(\mathrm{H}), \mathrm{MPa}\end{array}$ \\
\hline 1. & $\begin{array}{l}\text { Initial polyimide film } \\
\text { Side } 1 \\
\text { Side } 2\end{array}$ & $\begin{array}{l}3.46 \pm 0.18 \\
3.51 \pm 0.15\end{array}$ & $\begin{array}{l}359 \pm 15 \\
362 \pm 9\end{array}$ \\
\hline 2. & $\begin{array}{l}\text { Polyimide film after treatment with } \\
\text { oxygen plasma ( } 24 \mathrm{~h} \text { ) } \\
\text { Side } 1 \text { (directed towards the oxygen } \\
\text { plasma flow) } \\
\text { Side } 2\end{array}$ & $\begin{array}{l}3.01 \pm 0.16 \\
3.49 \pm 0.17\end{array}$ & $\begin{array}{l}305 \pm 7 \\
357 \pm 10\end{array}$ \\
\hline 3. & $\begin{array}{l}\text { Initial PI/POSS nanocomposite film } \\
\text { Side } 1 \\
\text { Side } 2\end{array}$ & $\begin{array}{l}4.21 \pm 0.15 \\
4.32 \pm 0.19\end{array}$ & $\begin{array}{l}215 \pm 11 \\
223 \pm 15\end{array}$ \\
\hline 4. & $\begin{array}{l}\text { PI/POSS nanocomposite film after } \\
\text { treatment with oxygen plasma }(24 \mathrm{~h}) \\
\text { Side } 1 \text { (directed towards the oxygen } \\
\text { plasma flow) } \\
\text { Side } 2\end{array}$ & $\begin{array}{l}5.01 \pm 0.16 \\
4.25 \pm 0.11\end{array}$ & $\begin{array}{l}302 \pm 35 \\
215 \pm 18\end{array}$ \\
\hline
\end{tabular}

without affecting the deep layers of the polymer [43]. According to flight experiments, the decrease in the surface layer in polymers is only a few $\mu$ m per year [44].

For the nanocomposite film containing the POSS structure, an increase in the elastic modulus is observed on one side of the nanocomposite film, to $\mathrm{E}=4.21 \pm 0.15 \mathrm{GPa}$, and on the other side to $\mathrm{E}=$ $4.32 \pm 0.19 \mathrm{GPa}$, as compared to the values of the PI film (Table 3). The close values of the modulus of elasticity of both surfaces of the PI/POSS nanocomposite film show the uniformity of the mechanical properties of the entire nanocomposite due to the high uniformity of the distribution of the filler throughout the sample volume. According to the literature data, the size of individual POSS particles is $20 \mathrm{~nm}$, but when they are introduced into a polymer matrix in the traditional way, they coagulate, which prevents a uniform distribution over the whole volume of the composite [45]. In this case, the size of the aggregates increases with an increase in the concentration of POSS in the PI. Therefore, the maximum optimal amount of POSS into a polymer (PI) matrix is $15 \mathrm{wt} \%$. With a higher addition of the filler, the resistance of the composite to atomic oxygen is significantly reduced [28]. Areas of increased erosion are formed - areas of the most intense interaction of the oxygen plasma with matter, or areas with an increased rate of chemical destruction and areas without damage (areas of accumulation of POSS particles). In this work, it was possible to achieve the introduction of more than $30 \mathrm{wt} \%$ POSS without particle aggregation.

In addition, the work [46] was found that the introduction of $5 \mathrm{wt} \%$ of POSS into a 3D-C/PI composite increases the Youngs's modulus of 3D-C/PI. However, upon further introduction of 3D-C/PI composite with 15 wt $\%$ of POSS has lower modulus than 3D-C/PI with 5 wt $\%$ POSS.

The superiority of this work is the use of the method of introducing POSS particles by introducing a PI (nuclear) membrane into the tracks prevents particle aggregation, which leads to the uniformity of the surface and improving mechanical properties of the entire nanocomposite and, accordingly, to increased resistance to the flow of oxygen plasma.

According to Table 3, it is noticeable that the effect of an oxygen plasma flow on the PI/POSS nanocomposite film leads to an increase in mechanical parameters compared to the initial values before processing, the elastic modulus and microhardness increased by 19 and $40 \%$, respectively. Such a significant increase in the mechanical properties of the nanocomposite film after treatment with oxygen plasma is associated with the formation of inorganic $\mathrm{SiO}_{2}$ particles (Fig. 7), which have an increased modulus of elasticity and microhardness as compared to the PI and POSS particles.

\section{Conclusions}

The possibility of producing polymer nanocomposite PI/POSS films based on PI track (nuclear) membranes by filling POSS tracks with structures in a high-pressure reactor has been established. By keeping the membranes at $250^{\circ} \mathrm{C}$ for $4 \mathrm{~h}$, the maximum achieved pore filling was $89 \%$

The introduction of POSS particles significantly increases the resistance of PI to oxygen plasma flow. The weight loss of the PI film reached $18.1 \pm 0.9 \mathrm{mg} / \mathrm{cm}^{2} 24 \mathrm{~h}$ after the start of the experiment, while the PI/ POSS nanocomposite film showed a slight change in weight $(0.92 \pm$ $0.05 \mathrm{mg} / \mathrm{cm}^{2}$ ). Chemical interaction of PI/POSS components with oxygen plasma particles leads to the formation of silicon dioxide particles with high protective properties, which prevents the deep penetration of atomic oxygen into the nanocomposite films.

The impact of an oxygen plasma flow on the PI/POSS nanocomposite film led to an increase in mechanical parameters compared to the initial values before treatment: the value of the elastic modulus increased from $\mathrm{E}=4.21 \pm 0.15 \mathrm{GPa}$ to $\mathrm{E}=5.01 \pm 0.16 \mathrm{GPa}$, and the microhardness increased from $\mathrm{H}=215 \pm 11 \mathrm{MPa}$ to $\mathrm{H}=302 \pm 35 \mathrm{MPa}$. The mechanical parameters of the side not directed to the oxygen plasma flow did not change. 


\section{Funding}

The work was supported by a project of the Russian Science Foundation (№19-79-10064).

\section{Declaration of competing interest}

The authors declare that they have no known competing financial interests or personal relationships that could have appeared to influence the work reported in this paper.

\section{References}

[1] J. Chen, D. Nengwen, Z. Li, W. Wang, Organic polymer materials in the space environment, Prog. Aero. Sci. 83 (2016) 37-56, https://doi.org/10.1016/j paerosci.2016.02.002.

[2] Y. Liu, L. Tang, L. Qu, S. Liu, Z. Chi, Y. Zhang, J. Xu, Synthesis and properties of high performance functional polyimides containing rigid nonplanar conjugated fluorene moietie, Chin. J. Polym. Sci. 37 (2019) 416-427, https://doi.org/ 10.1007/s10118-019-2225-0.

[3] R. Yokota, Recent trends and space applications of polyimides, J. Photopolym. Sci. Technol. 12 (1999) 209-216, https://doi.org/10.2494/photopolymer.12.209.

[4] H. Shimamura, T. Nakamura, Mechanical properties degradation of polyimide films irradiated by atomic oxygen, Polym. Degrad. Stabil. 94 (2009) 1389-1396, https://doi.org/10.1016/j.polymdegradstab.2009.05.013.

[5] M.Z. Naser, A.I. Chehab, Chapter 14 - polymers in space exploration and commercialization, in: Mariam Al Ali Al Maadeed, Deepalekshmi Ponnamma, Marcelo A. Carignano (Eds.), Polymer Science and Innovative Applications, Elsevier, 2020, pp. 457-484, https://doi.org/10.1016/B978-0-12-8168080.00014-7.

[6] M. Tagawa, K. Yokota, Atomic oxygen-induced polymer degradation phenomena in simulated LEO space environments: how do polymers react in a complicated space environment? Acta Astronaut. 62 (2008) 203-211, https://doi.org/10.1016/j. actaastro.2006.12.043.

[7] W. Zhao, W. Li, H. Liu, L. Zhu, Erosion of a polyimide material exposed to simulated atomic oxygen environment, Chin. J. Aeronaut. 23 (2010) 268-273, https://doi.org/10.1016/S1000-9361(09)60215-6.

[8] M. Qian, G. Liu, B. Zhou, X.Y. Xuan, Y.P. Niu, S.Q. Gong, Atomic oxygen durable ultra-black polyimide nanocomposite films in solar spectrum, Polym. Degrad. Stabil. 175 (2020), 109133, https://doi.org/10.1016/j. polymdegradstab.2020.109133.

[9] U. Andropova, O. Serenko, N. Tebeneva, A. Tarasenkov, M. Buzin, E. Afanasyev, D. Sapozhnikov, S. Bukalov, L. Leites, R. Aysin, A. Polezhaev, A. Naumkin, L. Novikov, V. Chernik, E. Voronina, A. Muzafarov, Atomic oxygen erosion resistance of polyimides filled hybrid nanoparticles, Polym. Test. 84 (2020), 106404, https://doi.org/10.1016/j.polymertesting.2020.106404.

[10] L.S. Novikov, V.N. Chernik, E.N. Voronina, K.B. Vernigorov, M.Yu Yablokova, Atomic oxygen influence on polymer nanocomposites with different fillers, J. Spacecraft Rockets 53 (2016) 1012-1018, https://doi.org/10.2514/1.A33495.

[11] M. Lv, Q. Wang, T. Wang, Y. Liang, Effects of atomic oxygen exposure on the tribological performance of $\mathrm{ZrO}_{2}$-reinforced polyimide nanocomposites for low earth orbit space applications, Compos. B Eng. 77 (2015) 215-222, https://doi. org/10.1016/j.compositesb.2015.03.029.

[12] F. Xiao, K. Wang, M. Zhan, Atomic oxygen erosion resistance of polyimide $/ \mathrm{ZrO}_{2}$ hybrid films, Appl. Surf. Sci. 256 (2010) 7384-7388, https://doi.org/10.1016/j. apsusc.2010.05.077.

[13] O.A. Anan'eva, V.K. Milinchuk, D.L. Zagorskii, Study of one-side aluminized polyimide films exposed on the Mir orbital space station, High Energy Chem. 41 (2007) 389-395, https://doi.org/10.1134/S001814390706001X.

[14] Y. Huang, X. Tian, S. Lv, R.K.Y. Fu, P.K. Chu, Mechanical and optical characteristics of multilayer inorganic films on polyimide for anti-atomic-oxygen erosion, Appl. Surf. Sci. 258 (2012) 5810-5814, https://doi.org/10.1016/j. apsusc.2012.02.104

[15] W. Chunbo, L. Liaoliao, J. Haifu, T. Dongbo, Q. Wei, L. Changwei, Z. Xiaogang, C. Chunhai, W. Daming, Atomic oxygen effects on silvered polyimide films and their surface modification by poly(siloxane amic acid) ammonium salts, RSC Adv. (2018) 21728-21734, https://doi.org/10.1039/C8RA03331E.

[16] Y.C. Chang, T.Z. Liu, H. Zhang, S.W. Duo, Protection of Kapton from atomic-oxygen erosion using a polysilazane coating, Appl. Mech. Mater. 651-653 (2014) 65-68. https://doi.org/10.4028/www.scientific.net/AMM.651-653.65.

[17] H. Mu, X. Wang, Z. Li, Y. Xie, Y. Gao, H. Liu, Preparation and atomic oxygen erosion resistance of $\mathrm{SiO}_{\mathrm{x}}$ coating formed on polyimide film by plasma polymer deposition, Vacuum 165 (2019) 7-11, https://doi.org/10.1016/j. vacuum.2019.03.047.

[18] J. Zhang, L. Ai, X. Li, X. Zhang, Y. Lu, G. Chen, X. Fang, N. Dai, R. Tan, W. Song, Hollow silica nanosphere/polyimide composite films for enhanced transparency and atomic oxygen resistance, Mater. Chem. Phys. 222 (2019) 384-390, https:// doi.org/10.1016/j.matchemphys.2018.10.022.

[19] R. Verker, E. Grossman, N. Eliaz, Erosion of POSS-polyimide films under hypervelocity impact and atomic oxygen: the role of mechanical properties at elevated temperatures, Acta Mater. 57 (2009) 1112-1119, https://doi.org/ 10.1016/j.actamat.2008.10.054.
[20] N.D.A. Mundari, A.K. Srivastava, K. Toyoda, M. Cho, Influence of atomic oxygen exposure on surface resistivity of silicon doped polyimide affecting spacecraft charging, Vacuum 105 (2014) 11-16, https://doi.org/10.1016/j. vacuum.2014.01.030.

[21] S. Duo, M. Li, M. Zhu, Y. Zhou, Resistance of polyimide/silica hybrid films to atomic oxygen attack, Surf. Coating. Technol. 200 (2006) 6671-6677, https://doi. org/10.1016/j.surfcoat.2005.09.028.

[22] X. Li, A. Al-Ostaz, M. Jaradat, F. Rahmani, S. Nouranian, G. Rushing, A. Manasrah, H. Alkhateb, M. Finckenor, J. Lichtenhan, Substantially enhanced durability of polyhedral oligomeric silsequioxane-polyimide nanocomposites against atomic oxygen erosion, Eur. Polym. J. 92 (2017) 233-249, https://doi.org/10.1016/j. eurpolymj.2017.05.004.

[23] Y. He, A. Suliga, A. Brinkmeyer, M. Schenk, I. Hamerton, Atomic oxygen degradation mechanisms of epoxy composites for space applications, Polym. Degrad. Stabil. 166 (2019) 108-120, https://doi.org/10.1016/j. polymdegradstab.2019.05.026.

[24] F. Liu, H. Guo, Y. Zhao, X. Qiu, L. Gao, Y. Zhang, Atomic oxygen-resistant polyimide composite fibers based on wet spinning of polyamic acid-POSS ammonium salts, Polym. Degrad. Stabil. 168 (2019), 108959, https://doi.org/ 10.1016/j.polymdegradstab.2019.108959.

[25] T.K. Minton, M.E. Wrigh, S.J. Tomczak, S.A. Marquez, L. Shen, A.L. Brunsvold, R. Cooper, J. Zhang, V. Vij, A.J. Guenthner, B.J. Petteys, Atomic oxygen effects on POSS polyimides in low earth orbit, ACS Appl. Mater. Interfaces 4 (2012) 492-502, https://doi.org/10.1021/am201509n.

[26] R. Verker, E. Grossman, I. Gouzman, N. Eliaz, POSS-polyimide nanocomposite films: simulated hypervelocity space debris and atomic oxygen effects, High Perform. Polym. 20 (2008) 475-491, https://doi.org/10.1177/ 0954008308089710.

[27] N. Atar, E. Grossman, I. Gouzman, A. Bolker, V.J. Murray, B.C. Marshall, M. Qian, T.K. Minton, Y. Hanein, Atomic-oxygen-Durable and electrically-conductive CNTPOSS-polyimide flexible films for space applications, ACS Appl. Mater. Interfaces 7 (2015) 12047-12056, https://doi.org/10.1021/acsami.5b02200.

[28] F. Liu, H. Guo, Y. Zhao, X. Qiu, L. Gao, Enhanced resistance to the atomic oxygen exposure of POSS/polyimide composite fibers with surface enrichment through wet spinning, Eur. Polym. J. 105 (2018) 115-125, https://doi.org/10.1016/j. eurpolymj.2018.05.022.

[29] B. Wu, Y. Zhang, D. Yang, Y. Yang, Q. Yu, L. Che, J. Liu, Self-healing anti-atomicoxygen phosphorus-containing polyimide film via molecular level incorporation of nanocage trisilanolphenyl POSS: preparation and characterization, Polymers 11 (2019) 1013, https://doi.org/10.3390/polym11061013.

[30] S. Duo, H. Ke, T. Liu, M. Song, M. Li, Surface modification of POSS-polyimide hybrid films by atomic oxygen using ECR plasma, Nucl. Instrum. Methods B. 307 (2013) 324-327, https://doi.org/10.1016/j.nimb.2012.10.036.

[31] S.W. Duo, M.M. Song, T.Z. Liu, C.Y. Hu, M.S. Li, Effect of atomic oxygen exposure on polyhedral oligomeric silsesquioxane/polyimide hybrid materials in low earth orbit environment, Key Eng. Mater. 492 (2011) 521-524. https://doi.org /10.4028/www.scientific.net/KEM.492.521.

[32] N.I. Cherkashina, V.I. Pavlenko, A.V. Noskov, N.I. Novosadov, E.S. Samoilova, Using multilayer polymer $\mathrm{PI} / \mathrm{Pb}$ composites for protection against X-ray bremsstrahlung in outer space, Acta Astronaut. 170 (2020) 499-508, https://doi. org /10.1016/j.actaastro. 2020.02.022.

[33] N.I. Cherkashina, V.I. Pavlenko, V.A. Manaev, O.V. Kuprieva, N.V. Kashibadze, E. S. Samoilova, Multilayer coatings based on polyimide track membranes and nanodispersed lead, Prog. Org. Coating 138 (2020), 105432, https://doi.org/ 10.1016/j.porgcoat.2019.105432.

[34] N.I. Cherkashina, Z.V. Pavlenko, E.S. Samoilova, N.I. Novosadov, Synthesis of nanofibers organosiloxane structures under hydrothermal conditions, IOP Conf. Ser. Mater. Sci. Eng. 828 (2020), 012005, https://doi.org/10.1088/1757-899X/ $828 / 1 / 012005$

[35] S.A. Smirnov, V.V. Rybkin, V.A. Titov, Influence of heterogeneous physicochemical processes on the parameters of low-temperature plasma, Russ. J. Gen. Chem. 85 (2015) 1260-1269, https://doi.org/10.1134/S1070363215050436.

[36] S.L. Koontz, L.J. Leger, S.L. Rickman, C.L. Hakes, D.T. Bui, D.E. Hunton, J.B. Cross, Oxygen interactions with materials III - mission and induced environments, J. Spacecraft Rockets 32 (1995) 475-482, https://doi.org/10.2514/3.26640.

[37] ASTM E 2089-00, Standart Practics for Ground Laboratory Atomic Oxygen Interaction Evaluation of Materials for Spacecraft Applications, 2006.

[38] S.W. Samwel, Low earth orbital atomic oxygen erosion effect on spacecraft materials, Space Res. J. 7 (2014) 1-13, https://doi.org/10.3923/sri.2014.1.13.

[39] P.R. Young, W.S. Slemp, The performance of selected polymeric materials exposed to low earth orbit, Polym. Adv. Technol. 9 (1998) 20-23, https://doi.org/10.1002/ (SICI)1099-1581(199801)9:1<20::AID-PAT729>3.0.CO;2-S.

[40] K.B. Vernigorov, A.Y. Alent'ev, A.M. Muzafarov, L.S. Novikov, V.N. Chernik, Erosion of polyimide modified by amorphous silica sol in the stream of oxygen plasma, J Synch Investig 5 (2011) 263-268, https://doi.org/10.1134/ S1027451011030190.

[41] R. Verker, E. Grossman, I. Gouzman, N. Eliaz, Residual stress effect on degradation of polyimide under simulated hypervelocity space debris and atomic oxygen, Polymer 48 (2007) 19-24, https://doi.org/10.1016/j.polymer.2006.10.035.

[42] R.C. Tennyson, Atomic oxygen and its effect on materials, in: R.N. DeWitt, D. Duston, A.K. Hyder (Eds.), The Behavior of Systems in the Space Environment, NATO ASI Series (Series E: Applied Sciences), vol. 245, Springer, Dordrecht, 1993, https://doi.org/10.1007/978-94-011-2048-7 10.

[43] V.I. Pavlenko, L.S. Novikov, G.G. Bondarenko, V.N. Chernik, A.I. Gaidar, N. I. Cherkashina, O.D. Edamenko, Experimental and physicomathematical simulation of the effect of an incident flow of atomic oxygen on highly filled 
polymer composites, Inorg. Mater. Appl. Res. 4 (2013) 169-173, https://doi.org/ 10.1134/S2075113313020135.

[44] B. Banks, Spacecraft Polymers Atomic Oxygen Durability Handbook, National Aeronautics and Space Administration, Washington, DC, 2014. Technical Report number: NASA-HDBK-6024.

[45] K.B. Vernigorov, A.Y. Alent'ev, I.B. Meshkov, A.M. Muzafarov, E.N. Voronina, L. S. Novikov, V.N. Chernik, Use of hyperbranched polyethoxysiloxane to improve the resistance of thermoplastic polyimide coatings to atomic oxygen environment,
Inorg. Mater. Appl. Res. 3 (2012) 81-87, https://doi.org/10.1134/ S2075113312020177.

[46] R. Shivakumar, A. Bolker, S.H. Tsang, N. Atar, R. Verker, I. Gouzman, M. Hala, N. Moshe, A. Jones, E. Grossman, T.K. Minton, E.H.T. Teo, POSS enhanced 3D graphene - polyimide film for atomic oxygen endurance in Low Earth Orbit space environment, Polymer 191 (2020), 122270, https://doi.org/10.1016/j. polymer.2020.122270. 